\title{
Ultrastructure of Spermatogenesis and Sperm Development in Saccocoelioides godoyi Kohn \& Froes, 1986 (Digenea, Haploporidae)
}

\author{
MFD Baptista-Farias ${ }^{+}$, A Kohn ${ }^{*}$, SC Cohen \\ Laboratório de Helmintos Parasitos de Peixes, Departamento de Helmintologia, Instituto Oswaldo Cruz, \\ Av. Brasil 4365, 21045-900 Rio de Janeiro, RJ, Brasil
}

Ultrastructural observations of spermatogenesis and sperm development of Saccocoelioides godoyi, an intestinal parasite of Leporinus friderici (Bloch, 1794) are described. The irregular-shaped spermatogonia form a peripheral layer, and show a prominent nucleus. Spermatocytes are larger than spermatogonia, and in the early stage present synaptonemal complex. Spermatids show nuclei smaller than the spermatocytes. Spermiogenesis is characterized by outgrowth of the zone of differentiation, presenting basal bodies, separated by an intercentriolar body. At the end of this process, the spermatozoa are released into the residual cytoplasmic mass. The spermatozoa of S. godoyi are elongate, similar to the pattern described for other Digenea, showing nuclei, mitochondria and two axonemes with the $9+1$ configuration. The peripheral cortical microtubules on the dorsal and ventral faces are laterally interrupted.

Key words: spermatogenesis - sperm development - Digenea - Saccocoelioides godoyi

Sperm ultrastructure and spermiogenesis have been used as tools for phylogeny in the parasitic Platyhelminthes (Justine 1991a, 1995, 1997). Most studies on sperm ultrastructure have been described in Monogenea (Justine 1992, 1993, Rohde \& Watson 1994a,b, Baptista-Farias et al. 1995, 1999, Hathaway et al. 1995, Watson et al. 1995, Watson \& Rohde 1995, Harris et al. 1997). Spermiogenesis presents minor differences in Digenea, suggesting different evolutionary levels within the groups (Hendow \& James 1988, Cifrian et al. 1993, Gracenea et al. 1997, Iomini \& Justine 1997). The present study describes the ultrastructure of spermatogenesis and the fine structure of the mature spermatozoon in a digenean species, Saccocoelioides godoyi, parasite of the freshwater fish, Leporinus friderici.

\section{MATERIALS AND METHODS}

S. godoyi was collected from the intestine of Leporinus friderici (Bloch 1794), Anostomidae,

\footnotetext{
${ }^{+}$Corresponding author. Fax: +55-21-260.4866. E-mail: bfarias@ioc.fiocruz.br

*Research fellow from Conselho Nacional de Desenvolvimento Científico e Tecnológico, CNPq.

Received 4 April 2000

Accepted 15 August 2000
}

from the reservoir of the Hydroelectric Power Station of Itaipu, Paraná River, Foz do Iguaçu, Brazil. Worms were fixed in $0.1 \mathrm{M}$ phosphate-buffered $2.5 \%$ glutaraldehyde, postfixed for one $\mathrm{h}$ in $1 \%$ osmium tetroxide in the same buffer, dehydrated in a graded ethanol series, and embedded in Epon (Luft 1961). Ultrathin sections were collected on copper grids, double-stained with $2 \%$ alcoholic uranyl acetate and lead citrate (Reynolds 1963) and observed in a Zeiss EM 900 electron microscope.

\section{RESULTS}

Examination of sections by transmission electron microscopy showed the testes surrounded by a continuous layer of connective tissue, presenting different stages of development.

The irregular-shaped spermatogonia form a peripheral layer, characterized by a prominent nucleus, showing a low cytoplasmic-nucleus ratio (Fig. 1). The spermatogonia nuclei appear oval or elongated with dense spots of chromatin distributed throughout the nucleoplasm. The cytoplasm matrix is electrondense due the presence of ribosomes, disposed in rosettes or polysome-like. Mitochondria and cisternae of endoplasmatic reticulum are present in cytoplasm but Golgi complex was not observed. Spermatogonia in the tertiary stage present mitochondria joined at the cell apex with the nucleus displaced to the base (Figs 1,2).

The tertiary spermatogonia divide mitotically giving rise to spermatocytes. These cells are the largest of the process, and show an increase cyto- 
plasmic-nucleus ratio. The nucleus presents sparse chromatin, arranged in small groups. The perinuclear space is not evidenced as in spermatogonia. The cytoplasm presents numerous mitochondria dispersed throughout it, endoplasmatic reticulum and free ribosomes, disposed in groups or rosettes (Fig. 3). Synaptonemal complexes, characteristic of this stage, were observed in the primary spermatocytes (Fig. 3, inset).

The spermatids nuclei are smaller than those of the spermatocytes, with small nucleolus and chromatin equally distributed in clumps or short and dense filaments. Free ribosomes in compact groups are observed in the cytoplasm of the spermatids (Fig. 1). In early spermatids, the mitochondria occupy a perinuclear position with dense matrix and longitudinal cristae.

As the spermatids differentiate, the formation of the zone of differentiation (ZD) is observed far from the nucleus, characterizing the beginning of spermiogenesis. In the ZD, a row of microtubules appears in the extremity of the spermatid, as support to the plasma membrane, forming a collar of fibrous dense material (Fig. 4).

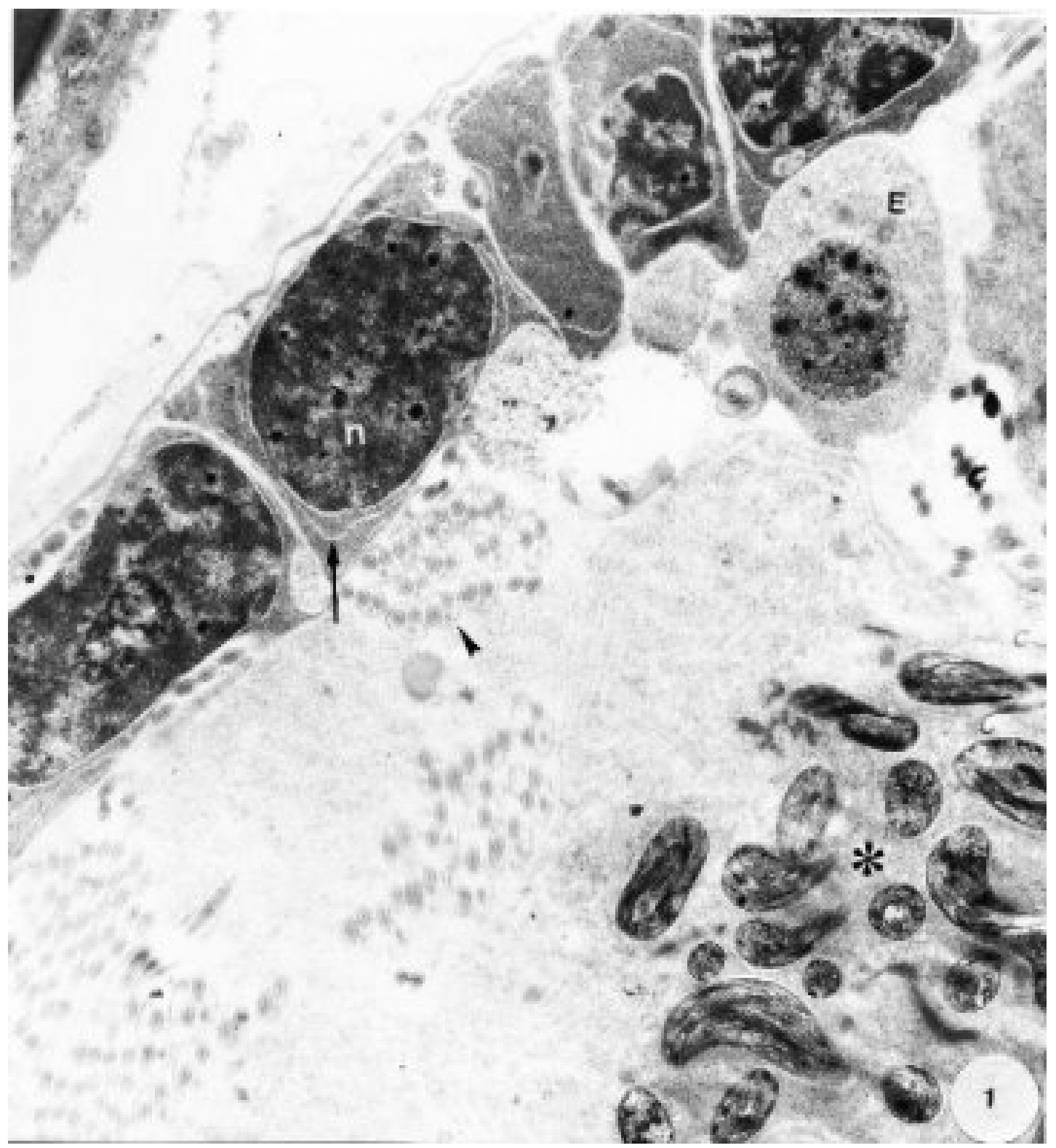

Spermatogenesis of Saccocoelioides godoyi. Fig. 1: spermatogonia in periphery of the testes, showing heterochromatic nuclei $(\mathrm{N})$, endoplasmatic reticulum cisternae (arrow), transversal sections of spermatozoa (arrowhead), early spermatids (E) and nuclei of the spermatids in the cytoplasmatic mass $\left(^{*}\right)$. X 10,100 
The ZD showing a section in the terminal portion contains peripheral microtubules and an intercentriolar body in development (Fig. 9). While the nucleus migrates to the peripheral cytoplasm, it elongates through the longitudinal axis of the cellular projection, changing its shape to cylindrical (Fig. 5). The chromatin become condensed and lamellar. In transverse sections, the lamellae present a hon- eycomb-like appearence. The nucleolus remains for a short time, appearing as small dense bodies (Figs $1,6,11)$. The two centrioles are orientate perpendicularly to the projection axis, on each side of the intercentriolar body (Fig. 9). The centrioles give rise to two free flagellae, and meanwhile the two striated rootlets, associated with each centriole, lie parallel to the intercentriolar body (Fig. 7).
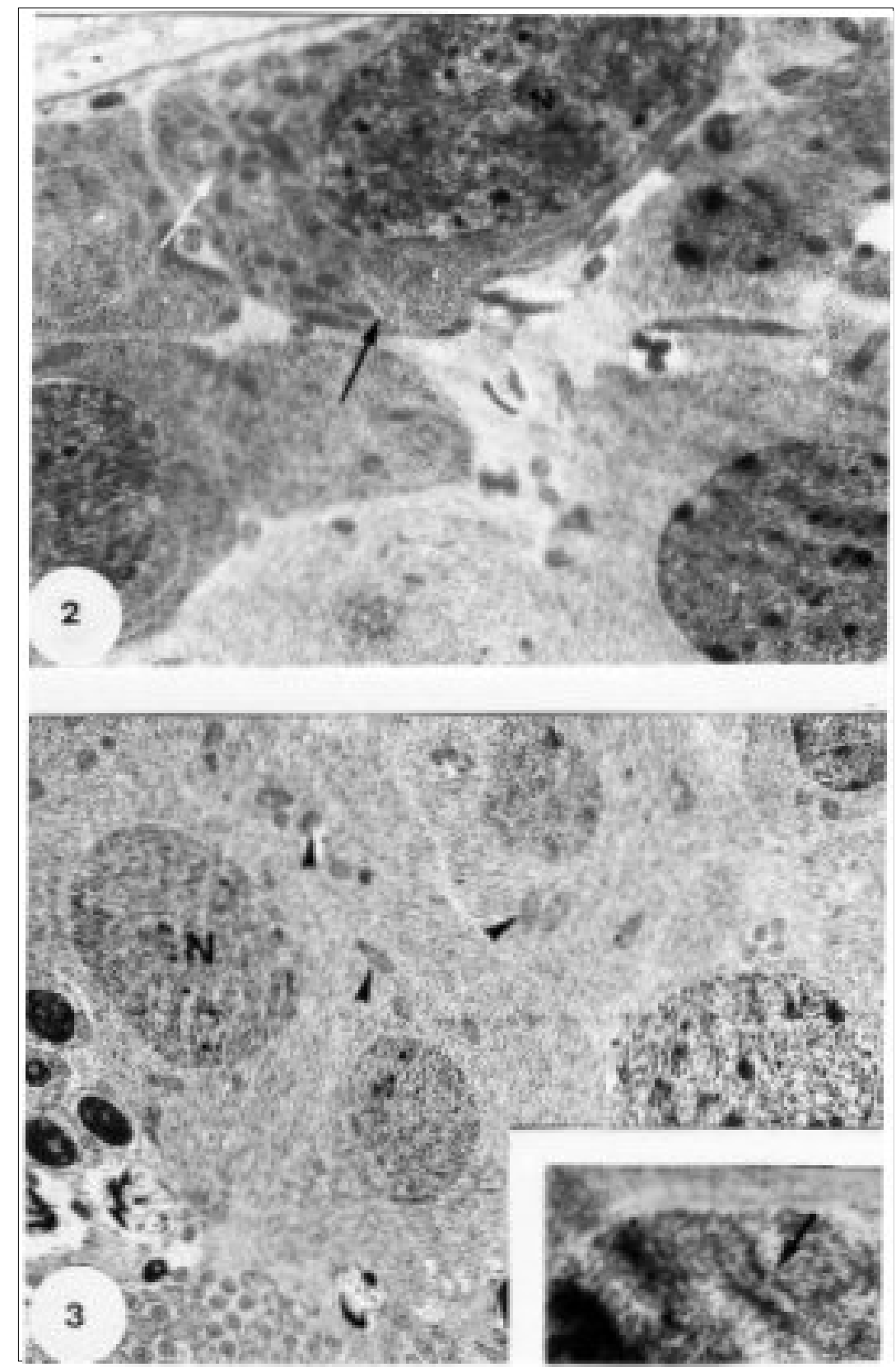

Spermatogenesis of Saccocoelioides godoyi. Fig. 2: spermatogonia in the tertiary stage with nuclei (N) into cell base, numerous mitochondria in the cell apex (white arrow) and endoplasmatic reticulum cisternae (black arrow). X 9,600. Fig. 3: spermatocytes showing nuclei with sparse chromatin $(\mathrm{N})$, mitochondria (arrowheads) and ribosomes. X 9,600. Inset: synaptonemal complex in the primary spermatocytes (arrow). X 16,000 
The axonemes line up parallel to the longitudinal axis of the median cytoplasmatic process. The striated rootlets, associated with the basal bodies, extend proximally on each side of the nucleus toward the common cytoplasmatic mass (Fig. 7).

At the proximal part of the median cytoplasmatic process (MCP), the plasma membrane becomes thicker forming a furrow-like, electrondense collar.
The nucleus continues to elongate and migrates to the distal position of the median process (Figs 7, 8). The mitochondria, which are in a perinuclear position of early spermatids, also migrate to the median process, forming a long cylindric body.

The MCP and the flagellae fuse along their lenghts. Before fusion, the MCP forms an electrondense depression with the flagellae proxi-
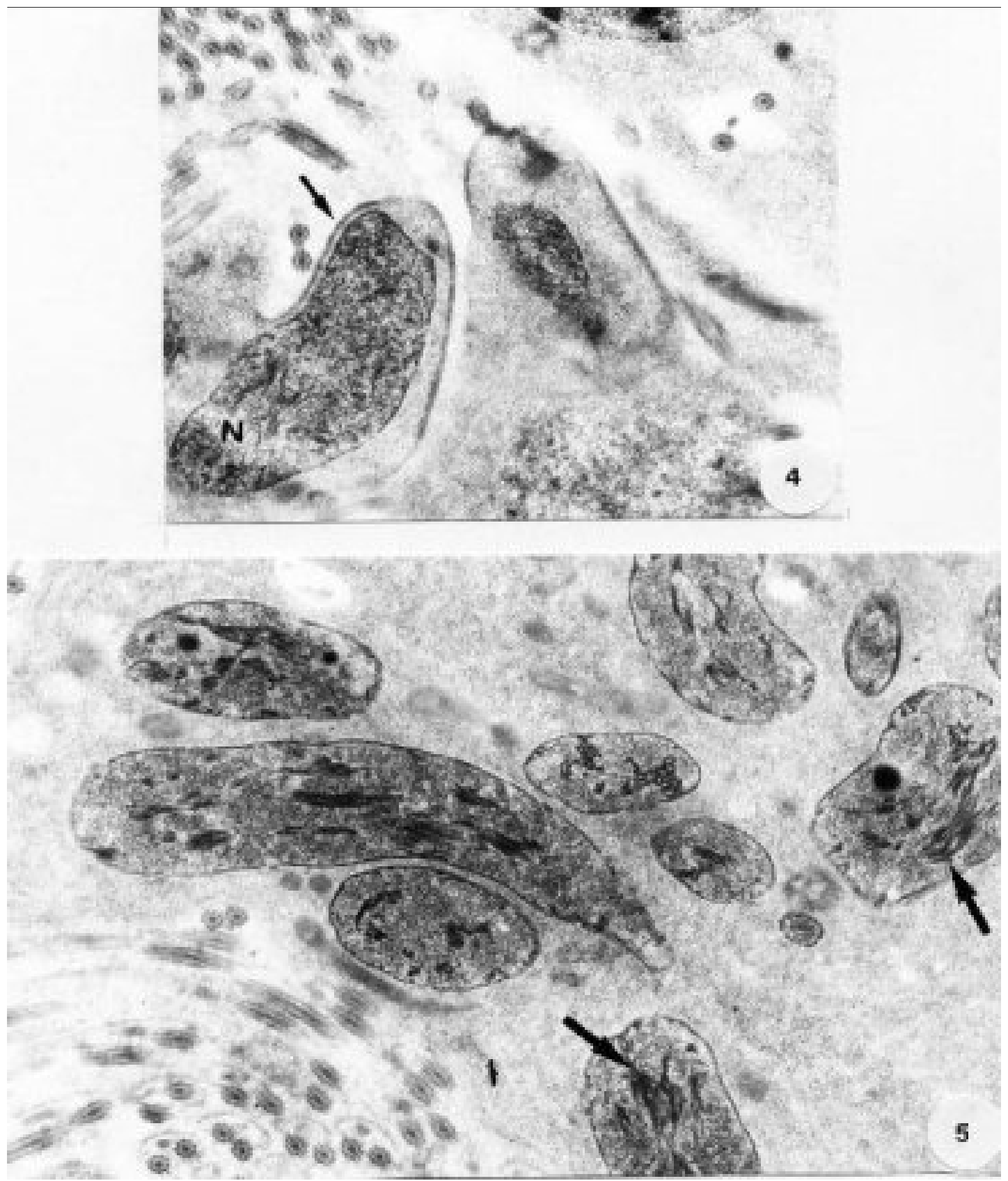

Spermiogenesis of Saccocoelioides godoyi. Fig. 4: zone of differentiation with the rising of fibrous material of the dense collar (arrow) and the elongation of the nucleus (N). X 14,000. Fig. 5: sections through nuclei of the spermatids in the cytoplasmatic mass showing the elongation of the nucleus and the chromatin becoming lamellar (arrows). X 6,300 


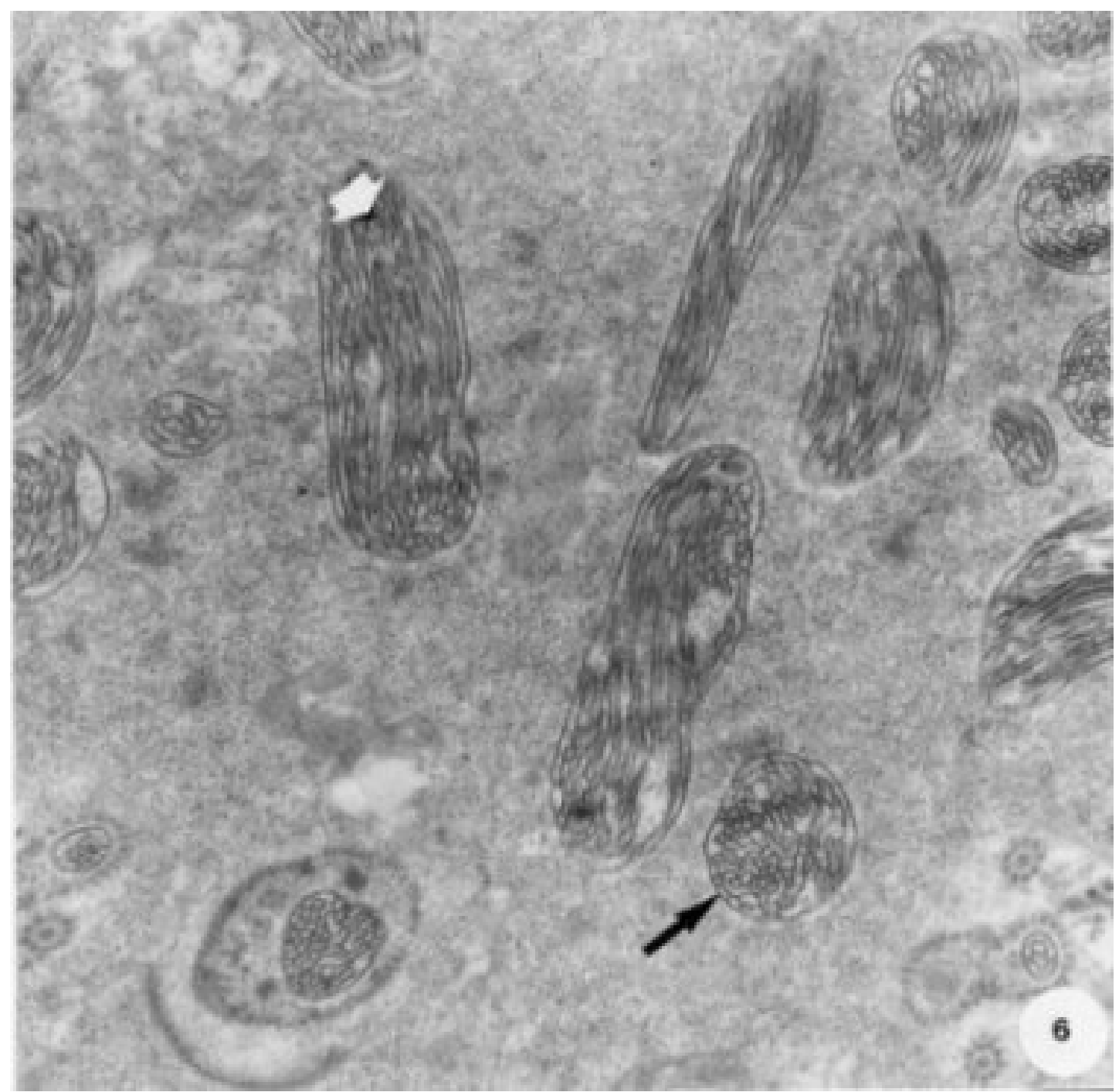

Spermiogenesis of Saccocoelioides godoyi. Fig. 6: transversal and longitudinal sections of spermatids nuclei, presenting lamellar chromatin (white arrow), with honeycomb appearence. X 26,400

mally situated (Fig. 10). When the flagellar membrane, and MCP are in contact, the electrondense material disappear and the flagellae are incorporated (Fig. 11). After fusion, sections through the base of the projection show two axonemes, and the microtubules sheath appear interrupted around them (Fig. 11, inset). In other sections, is possible to observe the cortical microtubules forming a complete ring around the spermatozoon (Fig. 12).

At the end of spermiogenesis, the diameter of the ZD decreases, the collar membranes approach and finally, the spermatozoon is released from the cytoplasmatic residual mass and its nucleus presents strongly condensed chromatin (Fig. 15).

The basal bodies and rootlets were never observed in the mature spermatozoa. These structures probably remain in the residual cytoplasm.

The main region of spermatozoon contains the nucleus, anterior portion of the mitochondria, the axonemes and a row of microtubules, which support the plasma membrane. Each axoneme consists of nine pairs of microtubules disposed around a central complex (Fig. 11). The ventral and dorsal plasma membranes are supported by a single row of microtubules, located parallel to the longitudinal axis of the cell.

The median region of the spermatozoon contains mitochondria, two axonemes and cortical microtubules, located just below the dorsal and ventral membranes (Figs 1, 12).

The terminal region extends from the distal extremity of the mitochondria to the posterior end 

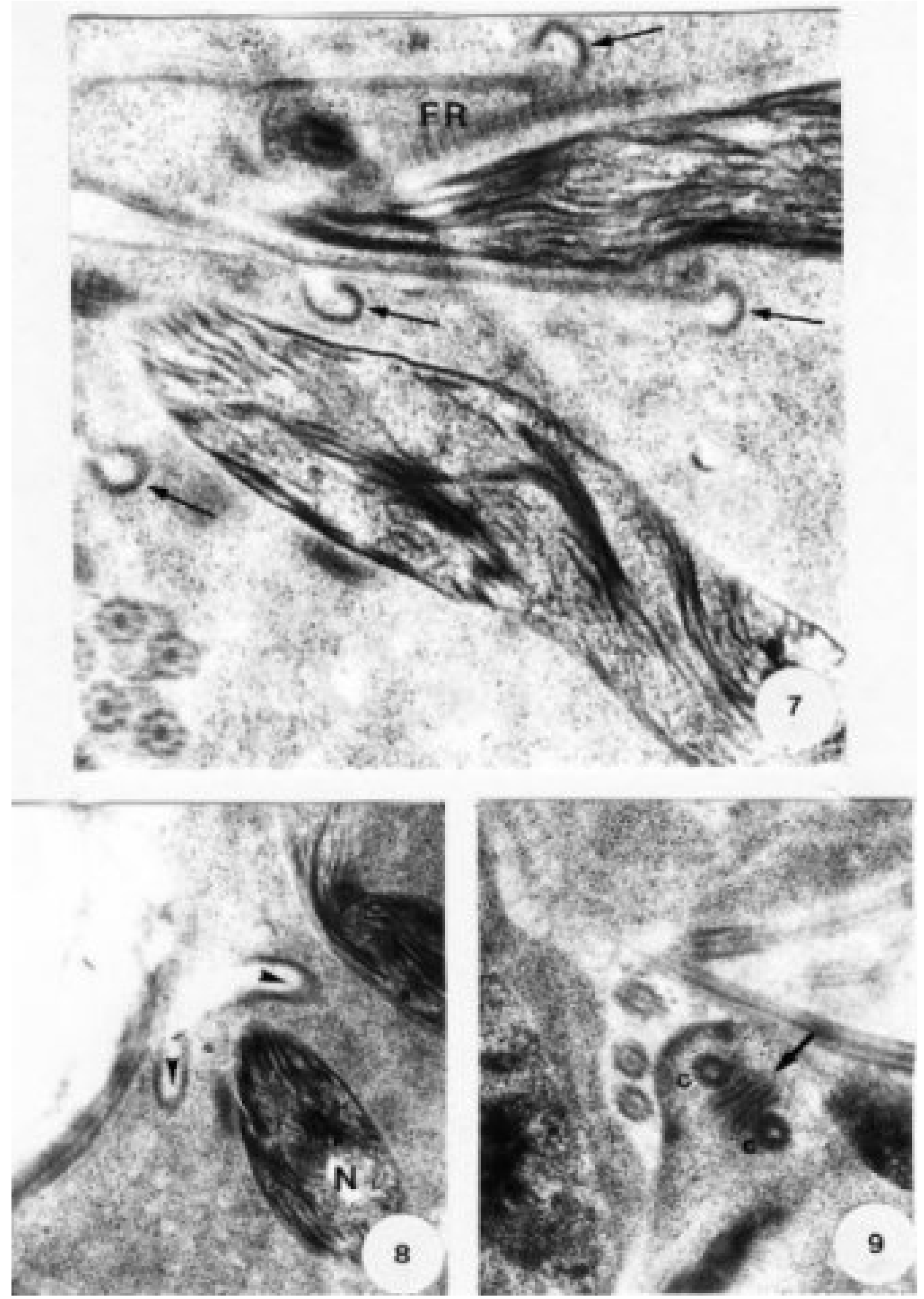

Spermiogenesis of Saccocoelioides godoyi. Fig. 7: high magnification of spermatids nuclei showing striated rootlets (FR), and the furrow-like electrondense collar (arrowheads). X 46,000. Fig. 8: elongation of the spermatid's nucleus (N) and thickening of the plasma membrana, forming a wrinkle-like, electrondense collar. X 24,200. Fig. 9: detail of the two centrioles on each side of the intercentriolar body (arrow). X 17,600 

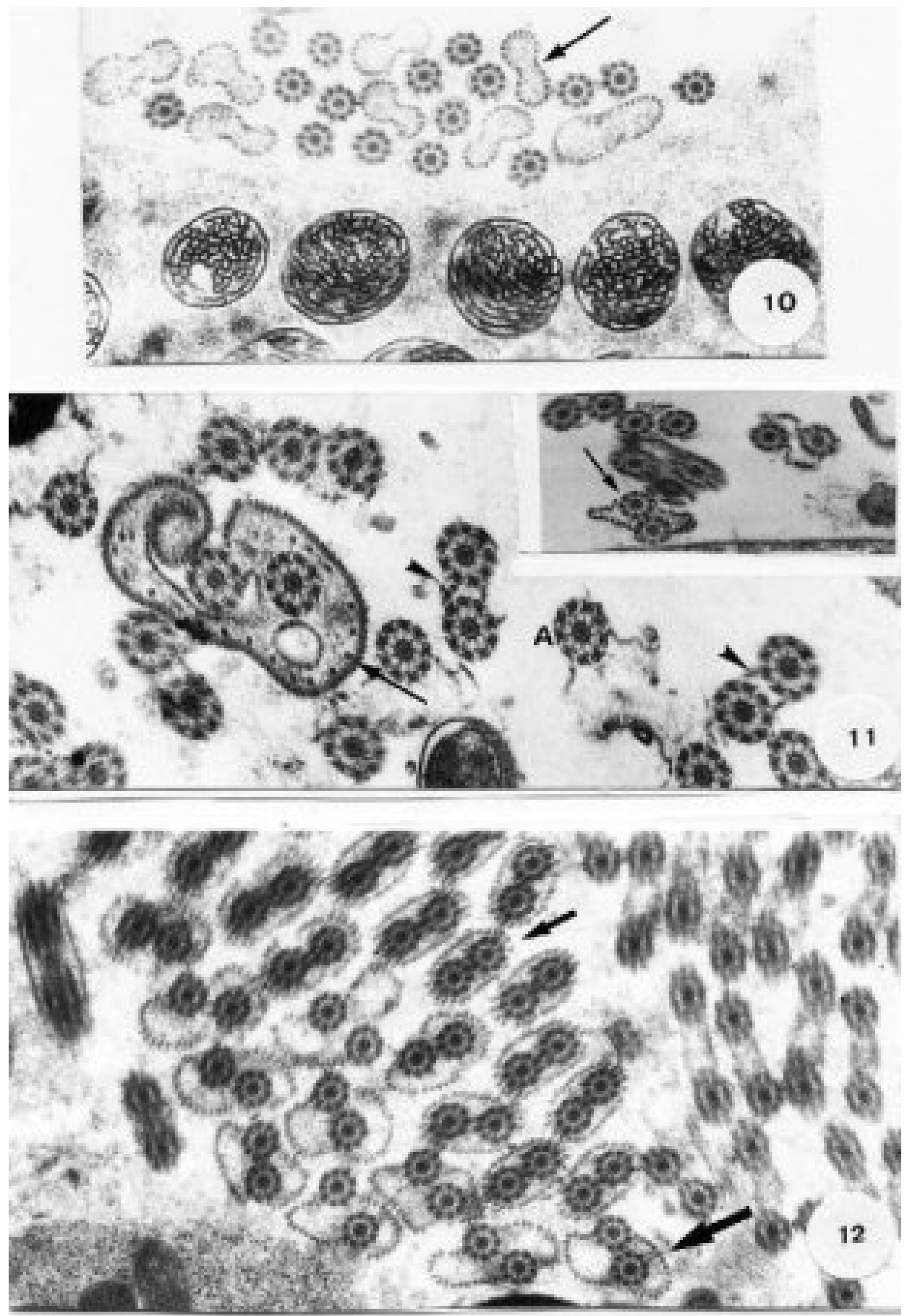

Sperm development of Saccocoelioides godoyi. Fig. 10: transversal section of spermatozoa in formation with the median cytoplasmatic process observing electrondense depression (arrow) and spermatid nuclei with honeycomb appearence of the chromatin. X 20,000. Fig. 11: transversal section through median cytoplasmatic process with the incorporation of the flagellae, presenting peripheral microtubules (arrow), axonemes (A), with the traditional configuration 9+1. Observe the terminal region of the spermatozoon with the remaining microtubules (arrowheads). X 48,000. Inset: two axonemes and the microtubules sheath interrupted around them. X 24,000. Fig. 12: transversal section through the beginning of the terminal region of the spermatozoon, showing a complete ring of cortical microtubules around the axonemes (little arrow) and microtubules situated beneath the dorsal and ventral membranes (large arrow). X 21,000 
of the spermatozoon. The anterior portion of the terminal segment is surrounded by cortical microtubules (Fig. 12) and in the final portion, the cell is narrower and presents just one or two remaining microtubules in the dorsal and ventral membranes (Fig. 11).

At the lumen of the spermatic duct, spermatozoa are observed in transverse and longitudinal sections (Figs 13, 14).

\section{DISCUSSION}

The ultrastructural organization of the tests and cytological transformations during the spermatogenesis and spermiogenesis in $S$. godoyi are in agreement with those reported for other Digenea, including Haematoloechus medioplexus (by Burton 1972), Cryptocotyle lingua (by Rees 1979), Corrigia vitta (by Robinson \& Halton 1982), Bucephaloides gracilescens (by Erwin \& Halton
1983), Postorchigenes gymnesicus (by Gracenea et al. 1997), Mesocoelium monas (by Iomini et al. 1997). The exceptions of this general pattern are Schistosoma mansoni that has one flagellum with a 9+1 and 9+0 configurations (Kitajima et al. 1976, Justine \& Mattei 1981) and Didymozoon sp. which has two flagellae with a 9+0 configuration (Justine \& Mattei 1983).

The synaptonemal complexes were readily observed in the primary spermatocytes of $S$. godoyi, a feature previously noted in other Digenea (Robinson \& Halton 1982).

In the species studied, the spermatids are distributed in the cytoplasmatic mass, in the periphery of which the cytological transformations occur as described for other Digenea (Robinson \& Halton 1982, Sharma \& Rai 1995).

The development of the ZD in the spermatids is followed by the formation of two free flagellae
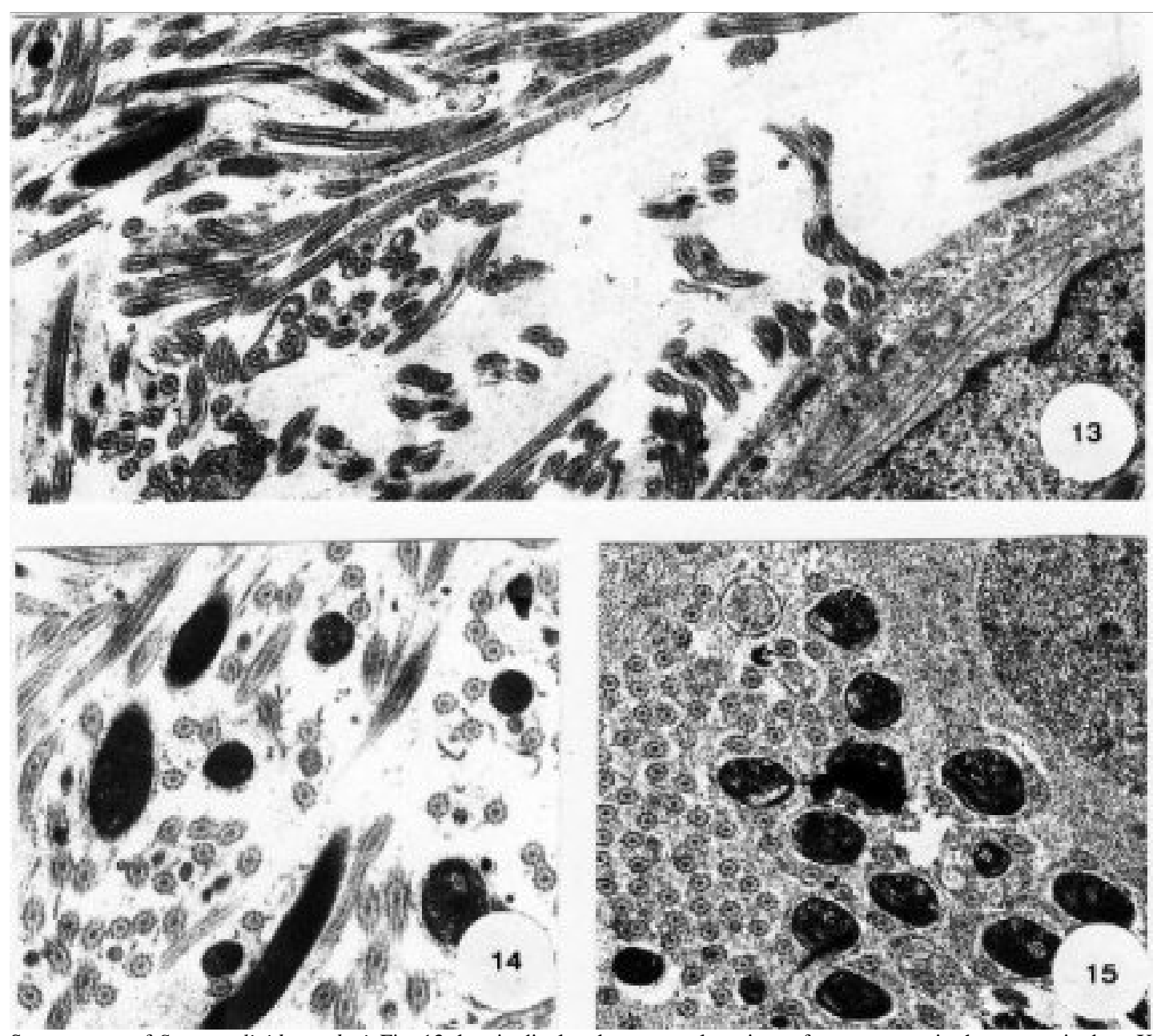

Spermatozoa of Saccocoelioides godoyi. Fig. 13: longitudinal and transversal sections of spermatozoa in the spermatic duct. $X$ 9,000. Fig. 14: detail of the anterior figure showing spermatozoa nuclei and axonemes in transversal and longitudinal section. X 10,800. Fig. 15: transversal section of the spermatozoa showing the nucleus with strongly condensed chromatin. X 10,000 
from basal bodies and by the penetration of the nucleus and mitochondria into the median cytoplasmatic process. Initially, the flagellae are free and posteriorly, they can fuse with MCP from the proximal region to the distal extremity of the spermatic cell. This proximal-distal fusion has also been observed in Aspidogastrea, Monogenea, Gyrocotylidae, Amphilinidea and Eucestoda (Justine 1991a).

Spermiogenesis in $S$. godoyi is similar to that described in most Digenea, consisting of a proximal-distal fusion on flagellar axonemes with a MCP, followed by an elongation of the spermatids. The presence of two centrioles and striated rootlets, and this fusion are general characteristics of parasitic Platyhelminthes (Justine 1991 a,b, 1995). The migration of the nucleus to the distal region of the differentiating spermatozoon observed in $S$. godoyi was previously reported in $H$. medioplexus, by Burton (1972), C. vitta by Robinson \& Halton (1982) and B. gracilescens by Erwin and Halton (1983), Maritrema linguilla by Hendow \& James (1988) and Paragonimus ohirai by Orido (1988).

The elongation of the nucleus in the longitudinal axis of the spermatid and the condensation of the chromatin into lamellae have already been observed in other Digenea (Burton 1972, Grant et al. 1976, Rees 1979).

The spermatozoa of $S$. godoyi are elongated and follow the pattern previously described for Digenea, similar to C. vitta (by Robinson \& Halton 1982). Transversal sections of the anterior region show two axonemes surrounded by a continuous row of microtubules, while the main region with nucleus and mitochondria presents two axonemes with the configuration 9+1 and peripheral cortical microtubules in the ventral and dorsal faces laterally interrupted. In this aspect, they are similar to the majority of species studied to date (Robinson \& Halton 1982, Zdarska et al. 1991, Sharma \& Rai 1995). Justine (1995) established that the structure found in the non-nuclear region presents a great variety among the taxon, and would be of great value for phylogenetic considerations within the group.

Iomini et al. (1997) stated that the lenght of axoneme may be used as a character for phylogeny in Digenea, and the number of axonemes have already been used in phyletic characterization in Monogenea (Justine 1991b) and Cestoda (Euzet et al. 1981, Bâ \& Marchand 1995).

According to Watson and Rohde (1992), the formation of two centrioles, an intercentriolar body and two axonemes initially free but which later rotate to lie parallel and eventually fuse with MCP is common in the spermiogenesis of many groups within Neodermata. However, it is possible to find exceptions within the same group, e.g. Gonapodasmius, Didymozoon, and members of the family Schistosomatidae, which live in pairs. Their different process of spermiogenesis, and sperm ultrastructure may be related to the biology of fertilization in species that live in pairs or are fused (Justine 1991a).

\section{ACKNOWLEDGEMENTS}

To the Superintendência do Meio Ambiente Aquático, Centro de Pesquisas and Dr Carla Canzi from Itaipu Binacional, for the facilities offered to examine the fish from the Paraná River. To Dr Monika Barth from Departamento de Virologia, Instituto Oswaldo Cruz, for the facilities offered for the use of the electron microscope.

\section{REFERENCES}

Bâ CT, Marchand M 1995. Spermiogenesis, spermatozoa and phyletic affinities in the Cestoda. Mem Mus Natl Hist Nat 166: 87-95.

Baptista-Farias MFD, Kohn A, Barth OM 1995. Ultrastructural aspects of spermatogenesis in Metamicrocotyla macracantha (Alexander, 1954) Koratha, 1955 (Monogenea; Microcotylidae). Mem Inst Oswaldo Cruz 90: 597-604.

Baptista-Farias MFD, Kohn A, Cohen SC 1999. Spermatogenesis and spermiogenesis in Microcotyle sp. (Microcotylidae, Monogenea). J Parasitol 85: 832838.

Burton PR 1972. Fine structure of the reproductive system of a frog lung fluke. III. The spermatozoon and its differentiation. J Parasitol 58: 68-83.

Cifrian B, Garcia-Corrales P, Martinez-Alos S 1993. Ultrastructural study of the spermatogenesis and mature spermatozoa of Dicrocoelium dendriticum (Plathelminthes, Digenea). Parasitol Res 79: 204-212.

Erwin BE, Halton DW 1983. Fine structural observations on spermatogenesis in a progenetic trematode, Bucephaloides gracilescens. Int J Parasitol 13: 413426.

Euzet L, Swiderski Z, Mokhtar-Maamouri F 1981. Ultrastructure comparée du spermatozoide des cestodoes. Relations avec la phylogenèse. Ann Parasitol Hum Comp 56: 247-259.

Gracenea M, Ferrer JR, González-Moreno O, Trullols M 1997. Ultrastructural study of spermatogenesis and the spermatozoon in Postorchigenes gymnesicus (Trematoda, Lecithodendriidae). J Morphol 234: 223-232.

Grant WC, Harkema R, Muse KE 1976. Ultrastructure of Pharyngostomoides procyonis Harkema 1942 (Diplostomatidae). I Observations on the male reproductive system. J Parasitol 62: 39-49.

Harris PD, Cable J, Tinsley RC 1997. Detection of sperm within Gyrodactylus (Platyhelminthes, Monogenea) tissues using fluorescence and transmission electron microscopy. Parasitol Res 83: 533-538.

Hathaway MA, Hathaway RP, Kritsky DC 1995. Spermatogenesis in Octomacrum lanceatum (Monogenoidea, Oligonchoinea, Mazocraeidea). Int $J$ Parasitol 25: 913-922. 
Hendow HT, James BL 1988. Ultrastructure of spermatozoon and spermatogenesis in Maritrema linguilla (Digenea:Microphallidae). Int J Parasitol 18: 53-63.

Iomini C, Justine JL 1997. Spermiogenesis and spermatozoon of Echinostoma caproni (Platyhelminthes, Digenea): transmission and scanning electron microscopy, and tubulin immunocytochemistry. Tissue Cell 29: 107-118.

Iomini C, Mollaret I, Albaret JL, Justine JL 1997. Spermatozoon and spermiogenesis in Mesocoelium monas (Platyhelminthes: Digenea): ultrastructure and epifluorescence microscopy of labelling of tubulin and nucleus. Folia Parasitol 44: 26-32.

Justine JL 1991a. Phylogeny of parasitic Platyhelminthes: a critical study of synapomorphis proposed on the basis of the ultrastructure of spermiogenesis and spermatozoa. Can J Zool 69: 1421-1440.

Justine JL 1991b. Cladistic study in the Monogenea (Platyhelminthes) based upon a parsimony analysis of spermiogenetic and spermatozoal ultrastructural characters. Int J Parasitol 21: 821-838.

Justine JL 1992. Ultrastructure of spermiogenesis, spermatozoa and the tegument in Atriaster sp. (Platyhelminthes, Monogenea, Polyopisthocotylea, Microcotylidae). Zool Scripta 21: 231-238.

Justine JL 1993. Phylogénie des monogènes basée sur une analyse de parcimonie des caractères de 1'ultrastructure de la spermiogenèse et des spermatozodes incluant les résultats récents. Bull $\mathrm{Fr}$ Pec Pisc 328: 137-155.

Justine JL 1995. Spermatozoal ultrastructure and phylogeny in the parasitic Platyhelminthes. Mem Mus Natn Hist Nat 166: 55-86.

Justine JL 1997. La classification générale des Plathelminthes parasites: changements récents et utilisation des caractères ultrastructuraux, en particulier des spermatozodes. Bull Soc Zool 123: 260-277.

Justine JL, Mattei X 1981. Étude ultrastructurale du flagelle spermatique des schistosomes (Trematoda: Digenea). J Ultrast Res 76: 89-95.

Justine JL, Mattei X 1983. A spermatozoon with two 9+0 axonemes in a parasite flatworm, Didymozoon (Digenea, Didymozoidae). J Submicr Cytol 15: 1101-1105.
Kitajima EW, Paraense WL, Correa LR 1976. The fine structure of Schistosoma mansoni sperm (Trematoda: Digenea). J Parasitol 62: 215-221.

Luft JH 1961. Improvements in eposci resin embebdingmethods. J Bioph Cyt 9, 409.

Orido Y 1988. Ultrastructure of spermatozoa of the lung fluke, Paragonimus ohirai (Trematoda: Troglotrematidae), in the seminal receptacle. J Morphol 196: 333-343.

Rees GF 1979. The ultrastructure of the spermatozoon and spermiogenesis in Cryptocotyle lingua ( Digenea: Heterophyidae). Int J Parasitol 9: 405-419.

Reynolds ES 1963. The use of lead citrate at high $\mathrm{pH}$ as electron opaque stain in electron microscopy. J Cell Biol 17: 208.

Robinson RD, Halton DW 1982. Fine structural observations on spermatogenesis in Corrigia vitta (Trematoda: Dicrocoeliidae). Z Parasitenkde 68: 53-72.

Rohde K, Watson NA 1994a. Ultrastructure of spermiogenesis and spermatozoa of Polylabroides australis (Platyhelminthes, Monogenea, Polyopisthocotylea, Microcotylidae). Parasite 1: 115-122.

Rohde K, Watson NA 1994b. Spermiogenesis in Gonoplasius sp. (Monogenea, Polyopisthocotylea, Microcotylidae). Acta Parasitol 39: 111-116.

Sharma PN, Rai N 1995. Ultrastructural study on spermatogenesis in Ganeo tigrinum, an intestinal trematode of Rana tigrina. J Helminthol 69: 77-84.

Watson NA, Rohde K 1992. Ultrastructure of sperm and spermatogenesis of Rugogaster hydrolagi, Schell 1973 (Platyhelminthes, Trematoda, Aspidogastrea, Rugogastridae). Parasitol Res 78: 516-524.

Watson NA, Rohde K 1995. Ultrastructure of spermiogenesis and spermatozoa of Neopolystoma spratti (Platyhelminthes, Monogenea, Polystomatidae). Parasitol Res 81: 343-348.

Watson NA, Whittington ID, Rohde K 1995. Ultrastructure of spemiogenesis and spermatozoa in the monogeneans Concinnocotyla australensis (Polystomatidae) and Pricea multae (Gastrocotylidae). Parasite 2: 357-366.

ZdárskáZ, Soboleva TN, Sterba J, Valkounova J 1991. Ultrastructure of the male reproductive system of the trematode Brachylaimus aequans. Folia Parasitol 38: 33-37. 